\section{Processes controlling carbon cycling in Antarctic glacier surface ecosystems}

E.A. Bagshaw ${ }^{1 *}$, M. Tranter ${ }^{2}$, J.L. Wadham ${ }^{2}$, A.G. Fountain ${ }^{3}$, A. Dubnick ${ }^{4}$, S. Fitzsimons ${ }^{5}$

\section{Abstract}

\section{doi: 10.7185/geochemlet.1605}

Glacier surface ecosystems, including cryoconite holes and cryolakes, are significant contributors to regional carbon cycles. Incubation experiments to determine the net production (NEP) of orgon ide range fresults, many of wich indicte that the system is net hetertrophic. We longer term inuls, McMurdo Dry Valleys, An exarine the tenporal variation of NEP in cryoconite from the McMurdo Dry Valleys, Antarctica to examine the effect of sediment disturbance on system production, and to understand processes controlling production over the lifetimes of glacier surface ecosystems. The shorter-term incubations have durations of one week and show net heterotrophy. The longer term incubations of approximately one year show net autotrophy, but only after a period of about 40 days ( 1000 hours). The control on net organic carbon production is a combination of the rate of diffusion of dissolved inorganic carbon from heterotrophic activity within cryoconite into the water, the rate of carbonate dissolution, and the saturation of carbonate in the water (which is a result of photosynthesis in a closed system). We demonstrate that sediment on glacier surfaces has the potential to accumulate carbon over timescales of months to years.

Received 15 September 2015 | Accepted 7 December 2015 | Published 21 January 2016

\section{Introduction}

Glacier surface ecosystems are significant sites of biological production in an otherwise nutrient poor landscape (Bagshaw et al., 2013). Meltwater flushed from glacier surfaces contains bioavailable carbon, which has the potential to stimulate production in downstream ecosystems (Lawson et al., 2014). Glacier

\footnotetext{
1 School of Earth and Ocean Sciences, Cardiff University, UK Corresponding author (email: BagshawE@Cardiff.ac.uk)

Bristol Glaciology Centre, School of Geographical Sciences, University of Bristol, UK

3 Portland State University, Portland, Oregon, USA

University of Alberta, Edmonton, Canada

5 University of Otago, Dunedin, New Zealand
}

surfaces in Antarctica host a variety of ecological niches, including cryoconite holes, cryolakes, and shallow supraglacial streams. The cryoconite holes and cryolakes are formed by rock debris on the surfaces melting into the ice as a consequence of solar heating. The debris is commonly fine-grained and aeolian transported, but can also be coarse material resulting from medial moraines or rock avalanches. Cryoconite holes are small ( 1-50 cm diameter, sediment depth $0.5-5 \mathrm{~cm}$ ), whereas cryolakes are larger (length scales $\sim 2-20 \mathrm{~m}$, sediment depth $0.5-10 \mathrm{~cm}$; Bagshaw et al., 2010). Antarctic cryolakes differ from larger and more commonly reported supraglacial lakes on Arctic glaciers by the presence of both a permanent layer of debris at the lake bottom and a persistent ice lid (Bagshaw et al., 2012), which also differentiates Antarctic cryoconite holes from their Arctic counterparts (Fig. S-1). Antarctic cryoconite holes persist for at least several years (Fountain et al., 2004) and host a variety of microorganisms, including cyanobacteria, tardigrades and rotifers (Christner et al., 2003), likely inoculated by wind-blown fragments of algal mats and desiccated microorganisms (Nkem et al., 2006). At shallow depths $(<1 \mathrm{~m})$ solar heating of the sediment melts the surrounding ice, so water is often present in these habitats, sealed beneath an ice cover of 3-20 cm, even when air temperatures are below $0{ }^{\circ} \mathrm{C}$ (Gribbon, 1979; Fountain et al., 2004). Cryolakes are the largest reservoirs of liquid water in the typically frozen supraglacial environment (Fountain et al., 2004). The organic carbon and nutrient stored can affect downstream ecosystems when organic compounds and nutrients are flushed from the glacier surface by periodic high melt rates (Bagshaw et al., 2010), eventually supporting enhanced biological activity in glacier forefields, lakes and streams (Foreman et al., 2004; Hood et al., 2015).

The production of organic carbon on glacier surfaces has received considerable attention over the last decade (Anesio and Laybourn-Parry, 2012). New autochthonous organic carbon accumulates when production (P, Eq. 1) is greater than respiration ( $R, E q .2)$. Some studies find that $P$ exceeds $R$ in cryoconite holes (Anesio et al., 2009), whilst others find that $\mathrm{R}$ exceeds $\mathrm{P}$ during the melt season (Stibal and Tranter, 2007; Bagshaw et al., 2011).

$$
\begin{aligned}
& \mathrm{CO}_{2}+\mathrm{H}_{2} \mathrm{O} \leftarrow===\Rightarrow \mathrm{CH}_{2} \mathrm{O}+\mathrm{O}_{2} \\
& \mathrm{CH}_{2} \mathrm{O}+\mathrm{O}_{2} \leftarrow===\Rightarrow \mathrm{CO}_{2}+\mathrm{H}_{2} \mathrm{O}
\end{aligned}
$$

In Antarctica, P is generally much lower in ice-lidded cryoconite holes than in their open Arctic counterparts (Hodson et al., 2010b). Reported rates of P range from 1.3 (Bagshaw et al., 2011) to $2.4 \mu \mathrm{g} \mathrm{C} \mathrm{g}^{-1} \mathrm{~d}^{-1}$ (Hodson et al., 2010b), compared with $20.9 \mu \mathrm{g} \mathrm{C} \mathrm{g}^{-1} \mathrm{~d}^{-1}$ (Telling et al., 2010) to $208 \mu \mathrm{g} \mathrm{C} \mathrm{L}^{-1} \mathrm{~d}^{-1}$ (Anesio et al., 2009) in cryoconite on Svalbard glaciers. Telling et al. (2010) elaborate on some of the methodological differences between these experiments. A plausible explanation for these apparently contradictory findings is that the microbially-dominated communities within ice-lidded cryoconite holes self-organise to recycle and redistribute resources, to balance $\mathrm{P}$ and $\mathrm{R}$ over longer timescales and maintain the longevity of the ecosystem. In Arctic systems, individual cryoconite holes do not tend to persist for multiple ablation seasons because sediment is more frequently mobilised by supraglacial meltwaters (Hodson et al., 2008). Instead, 
cryoconite granules form, which consist of polymer-bound sediment particles and microorganisms (Langford et al., 2010; Takeuchi et al., 2010) and likely maintain ecosystem longevity. Longer term trends in $\mathrm{P}$ and $\mathrm{R}$ are unlikely to be captured by traditional incubation techniques, which typically have durations of 24 hours. Incubations also disturb and/or mix the surface of the $\mathrm{cm}$-deep sediment layer (Bagshaw et al., 2013), where autotrophic microorganisms are concentrated, with deeper sediment in which heterotrophic microorganisms flourish. This is similar to observations in cryoconite granules, where photosynthetic organisms are concentrated on the exterior of polymer-bound particles and heterotrophs are found in the interior (Langford et al., 2010; Takeuchi et al., 2010). We contend that there is a need to conduct longer term incubations over periods more representative of the whole melt season in order to examine the interplay between autotrophic processes at the sediment surface and heterotrophic processes within the deeper sediment.

We report a combination of one week in-field incubations at Canada Glacier $\left(77.6167^{\circ} \mathrm{S}, 162.9833^{\circ} \mathrm{E}\right)$, and longer term laboratory experiments, equivalent to two melt seasons, on cryolake sediments from Joyce Glacier (78.0243 ${ }^{\circ} \mathrm{S}, 163.7788^{\circ} \mathrm{E}$ ) (Fig. S-1), both in the McMurdo Dry Valleys, Antarctica. These incubations are much longer than those published to date, which are typically 24 hours in duration. Our aim is both to quantify the rates of P and R within cryolake sediment on these timescales, and to assess the interplay of microbial processes on the sediment surface and within the body of the sediment. We use these data to assess whether Antarctic cryolake ecosystems are in a state of net production or consumption of organic carbon.

\section{Methods}

Standard cryoconite incubation methods using oxygen microoptodes were employed (Hodson et al., 2010b; Telling et al., 2010; Bagshaw et al., 2011), with experiment durations of one week for field incubations and 150 days for laboratory experiments. We equate dissolved oxygen concentration with carbon production (Telling et al., 2010). Briefly, the field experiments were run in situ using cryolake sediment from Canada Glacier, and laboratory experiments with incubated cryolake sediment from Joyce Glacier in conditions which mimic the glacier surface in terms of temperature, light and gas exchange. Uniform sediment depth of $1 \mathrm{~cm}$ was employed in all incubations. Full details of methods, instruments and analyses are available in the Supplementary Information.

\section{Results}

The mean organic carbon (OC) and inorganic carbon (IC) content of the Joyce Glacier cryolake sediment were $0.12 \pm 0.03 \%(n=6)$ and $0.34 \pm 0.03 \%$ $(n=6)$, respectively. For comparison, Canada Glacier cryoconite OC and IC were
$0.18 \pm 0.23 \%(n=117)$ and $0.07 \pm 0.11 \%(n=10)$, respectively. The porosity of the sediment was $34 \pm 11 \%(n=117)$. Heterotrophic processes $(R)$ dominated throughout the 200 hour field experiment (Fig. 1). Oxygen decreased systematically over the first 100 hours in both the dark and light bottles. The absolute values of $\mathrm{P}, \mathrm{R}$ and NEP are shown in Figure $1 \mathrm{~b}$, and are of the order of several $\mu \mathrm{g} C$ per gram of wet sediment throughout the experiment. This is consistent with data reported by Hodson et al. (2010a) for incubations of cryoconite from Blue Ice in East Antarctica.
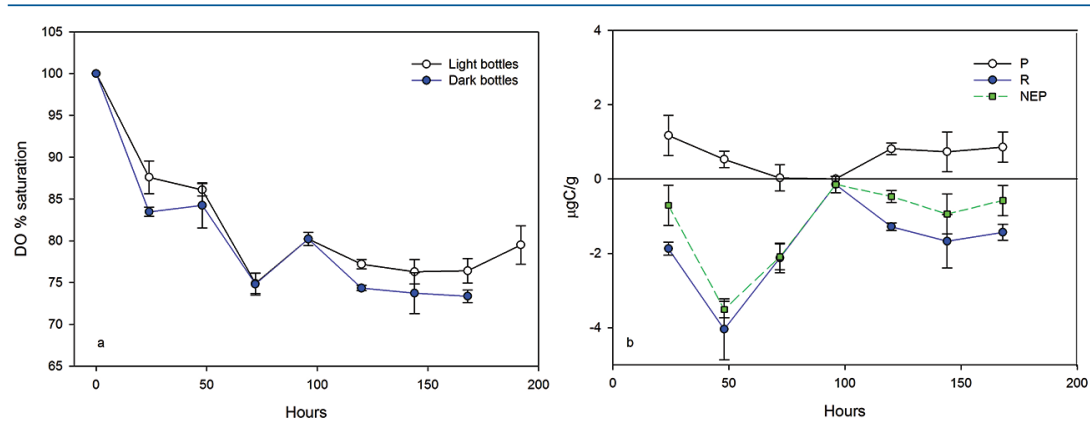

Figure 1 (a) Oxygen concentrations in dark and light bottles during the $200 \mathrm{hr}$ incubation of cryolake sediment from Canada Glacier with (b) corresponding values of $\mathrm{P}, \mathrm{R}$ and NEP.

Dissolved oxygen (DO) variations in the long-term laboratory incubations of cryolake sediment from Joyce Glacier also show net heterotrophy during the first week (200 hr, Fig. 2), and DO concentrations in the light and dark bottles again show strong similarity. The DO concentrations begin to diverge after 380 hr (16 d), with the light bottles eventually becoming supersaturated after 1000 $\mathrm{hr}(40 \mathrm{~d})$. The DO concentrations in the light bottles increase to $140 \%$ saturation after $250 \mathrm{hr}$, a value that has been observed in cryoconite holes on Canada Glacier (Tranter et al., 2004; Bagshaw et al., 2011). The dark bottles become increasingly undersaturated, falling to values of $23 \%$.

The overall NEP in these long term incubations is $110 \mu \mathrm{g} \mathrm{C}$. The dissolved inorganic carbon (DIC) content in the deionised water at the start of the experiment was $~ 32.2 \mu \mathrm{eq} \mathrm{L}^{-1}$, or $39 \mu \mathrm{g} \mathrm{C}$, as calculated by PHREEOC assuming that the $100 \mathrm{ml}$ water is at $0{ }^{\circ} \mathrm{C}$ and in equilibrium with an atmospheric $\mathrm{CO}_{2}$ concentration of $380 \mathrm{ppm}$. Since the OC content of the sediment was $0.12 \%$, the $\sim 25 \mathrm{~g}$ of wet sediment contained $\sim 20 \mathrm{mg} \mathrm{C}$ (water content of $34 \%$ ). These calculations demonstrate that the initial water does not contain sufficient DIC to account for all the new organic matter fixed on the surface, and suggests that carbon must be transferred via respiration in the sediment body to the surface to make up the shortfall in available DIC. 


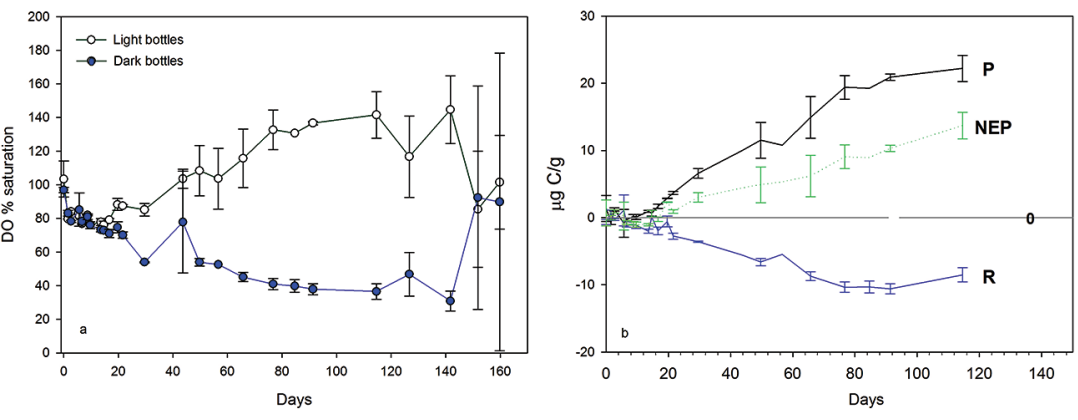

Figure 2 (a) Oxygen concentrations in dark and light bottles during the long term (one year) incubation of cryolake sediment from Joyce Glacier. (b) Corresponding values of $P, R$ and NEP.

\section{Discussion}

Conceptual model. The initial stages of the longer term incubations (Fig. 2) are similar to the shorter term incubations (Fig. 1), in that both sets of incubations show unequivocal net heterotrophy over timescales of $\sim 8$ days. This is consistent with other studies which use $24 \mathrm{hr}$ incubation of cryoconite from Antarctica (Hodson et al., 2010a,b; Bagshaw et al., 2011; Hodson et al., 2013). However, the longer term incubations suggest that more complex interactions control the overall $\mathrm{C}$ balance, with net heterotrophy shifting to net autotrophy over timescales of $>\sim 20$ days. Phototrophs in the sediment only fix organic carbon in the illuminated zone, often forming mat-like features (Hodson et al., 2010b). The phototrophs were physically disturbed during transfer of the sediment into the incubation bottles at the start of the experiment, so we hypothesise that they can only begin to colonise the surface layer after the experiment begins. Consistent with this were the green-coloured algal mats and granules, visible on the sediment surface by the end of our longer light incubation, which have occasionally been observed in the field. By contrast, the heterotrophic community is less sensitive to physical disturbance and may even be stimulated by the burial of fresh surface organic matter, so it is unsurprising that the incubations show net heterotrophy during the initial stages.

A simple conceptual model of $\mathrm{O}_{2}$ and DIC fluxes into and out of the sediment accounts for the observed changes in NEP. Figures 2 and 3(d-f) show that during the first days of the incubation $(<50 \mathrm{hr})$ in the light bottles, rates of heterotrophic activity in the sediment are greater than the rate of photosynthesis in the surface layer. Hence, oxygen concentrations become lower in the sediment, and consequently there is net diffusion of oxygen from the overlying water into the sediment. Simultaneously, the relatively high rate of heterotrophic activity in the sediment results in elevated concentrations of DIC, and so there is diffusion of DIC from the sediment into the overlying water. Gradually, the phototrophs increase in biomass, and start to elevate $\mathrm{O}_{2}$ concentrations in the water, utilising DIC diffusing up through the sediment. Continued heterotrophic activity deeper in the sediment further depletes sediment $\mathrm{O}_{2}$. The rate of heterotrophic activity is likely to diminish over time at depth, as more labile organic matter sources are exhausted and DO concentrations diminish. Near surface layers, in closer diffusive contact with $\mathrm{O}_{2}$ production, maintain higher $\mathrm{DO}$ concentrations. In the dark bottles, there are no phototrophic processes, and so concentrations of DO decrease continuously in both the water and sediment (Fig. 3a-c).

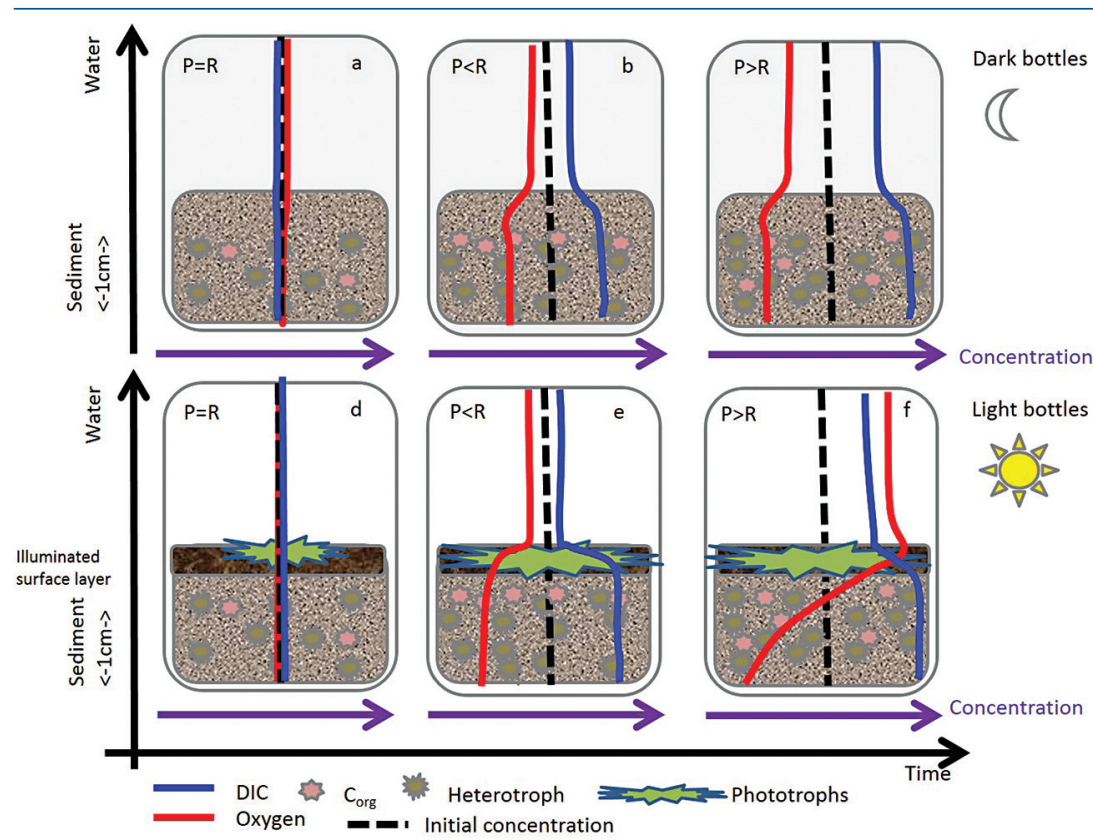

Figure 3 Conceptual model of the exchange of oxygen and DIC between the water column, heterotrophs in the deeper sediment layers and phototrophs concentrated at the sediment surface, during early $(a, d)$ middle $(b, e)$ and later $(c, f)$ stages of the long-term incubation in the dark $(a-c)$ and dark $(d-f)$ bottles. The panels are ordered left to right by time into the experiment, and the $\mathrm{x}$-axis of each panel represents DIC and $\mathrm{O}_{2}$ concentrations relative to starting values (dotted line).

Geochemical balancing. Heterotrophic activity in the sediment generates $\mathrm{CO}_{2}$, which is used in photosynthesis, but also dissolves carbonate minerals (Eq. 3). The chemical composition of the final dark and light bottles is consistent with this assertion, since both $\mathrm{Ca}^{2+}$ and $\mathrm{HCO}_{3}{ }^{-}$have increased. The final DIC concentrations are 761 and $241 \mathrm{ueq} \mathrm{\textrm {L } ^ { - 1 }}$ respectively, and this presents, superficially, a problem with the calculation of $\mathrm{P}$ and $\mathrm{R}$ from DIC changes. If all the DIC was derived from heterotrophic reactions in the sediment, and the initial DIC concentration of the water was $32.2 \mu \mathrm{mol} \mathrm{L}^{-1}$, then $\mathrm{R}$ would be equivalent 
to $913 \mu \mathrm{g} \mathrm{C}$, and P equivalent to $289 \mu \mathrm{g}$ C. This implies that the incubation is net heterotrophic, and that $624 \mu \mathrm{g} C$ net of organic matter has been assimilated within the sediment, which is at odds with the conclusions reached based upon changes in DO alone.

$$
\mathrm{CaCO}_{3}+\mathrm{CO}_{2}===\rightarrow \mathrm{Ca}^{2+}+2 \mathrm{HCO}_{3}
$$

The large discrepancy with the net autotrophy suggested by the DO changes $(+110 \mu \mathrm{g}$ C vs $-624 \mu \mathrm{g}$ C), can be resolved by considering the geochemical balance of the incubation. Heterotrophic activity in the sediment produces $\mathrm{CO}_{2}$ which chemically weathers carbonate and silicate minerals in the sediment. This causes an increase in $\mathrm{Ca}^{2+}, \mathrm{Mg}^{2+}, \mathrm{K}^{+}$and $\mathrm{HCO}_{3}{ }^{-}$in the sediment pore waters, which diffuse into the overlying waters. However, the concentration of these species is very different between the final light and dark bottles (Table 1). Photosynthesis in a closed aquatic system increases the $\mathrm{pH}$ of the solution and causes increasing saturation with aragonite and calcite (Table 1; Tranter et al., 2004). It is notable that Table 1 shows that water is approximately saturated with calcite and aragonite in the light bottles, but is under-saturated in the dark bottles. Hence, as heterotrophic activity within the sediment causes $\mathrm{Ca}^{2+}$ and $\mathrm{HCO}_{3}{ }^{-}$to diffuse through the illuminated sediment surface into the overlying water, photosynthesis, predominantly at the sediment-water interface, saturates the waters and causes carbonate precipitation (Eq. 4). The latter prevents high accumulation of DIC in the light bottles, in contrast to the dark bottles. The actual concentration of $\mathrm{Ca}^{2+}$ and DIC found in solution is thus a kinetic balance between the rate of diffusion of $\mathrm{Ca}^{2+}$ and DIC from the sediment and the rate of photosynthesis. This is a similar scenario to that found at the seafloor (Wilson et al., 1985).

$$
\mathrm{Ca}^{2+}+\mathrm{HCO}_{3}{ }^{-}+\mathrm{OH}^{-}===\rightarrow \mathrm{CaCO}_{3}+\mathrm{H}_{2} \mathrm{O}
$$

The oxygen depletion in the dark bottle is $\sim 340 \mu \mathrm{eq} \mathrm{L} \mathrm{L}^{-1}$. The measured

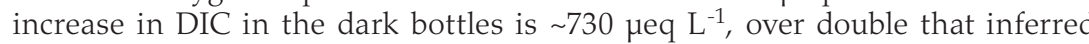
from the oxygen measurements. This suggests that carbonate minerals are being dissolved in the sediment, rather than silicate minerals, since one mole of rock DIC is liberated for each mole of $\mathrm{CO}_{2}$ generated from oxidation of organic matter This supports our assertion that carbonate dissolution supplies the additional DIC for the positive NEP that was measured.

Significance for carbon budgets. These results demonstrate that glacier surface ecosystems such as cryolakes and cryoconite holes can exist in a state of net production. Processes of carbon cycling have long been documented in cryoconite holes (Tranter et al., 2004; Bagshaw et al., 2007; Foreman et al., 2007; Stibal and Tranter, 2007), but the extent of the dependence of photosynthetic organisms concentrated at the surface of the sediment layer on heterotrophic processes deeper in the sediment has not been fully discussed in the literature to date. This inter-dependence may also help explain the link between sediment depth and $\mathrm{P}: \mathrm{R}$ balance previously observed in short term (6-24 hr) cryoconite incubations (Telling et al., 2012). The heterotrophic activity in the deeper sediment serves to relocate organic matter, fixed as $\mathrm{CO}_{2}$, from the deeper layers to the surface of the sediment, and to dissolve carbonate minerals. Should the carbonate minerals be ancient, then the new organic matter fixed from their dissolved DIC will be old in radiocarbon terms. It follows that extracellular exudates and the contents of lysed and partially degraded cells this otherwise new, yet radiocarbon old, organic matter, will produce radiocarbon old dissolved OC (DOC). This combination of processes may help to explain why labile DOC in supraglacial runoff is radiocarbon old (Lawson et al., 2014; Hood et al., 2015). Microbes on glacier surfaces may utilise this ancient DOC in their metabolic processes and augment it with organic matter fixed from the dissolution of ancient carbonates.

Table 1 Initial deionised water (DIW) concentration and final concentrations of major ions, $\mathrm{DO}$ (\% saturation), $\mathrm{pH}$ and the Saturation Index (SI) of calcite and aragonite in incubation waters DO (\% saturation), $\mathrm{pH}$ and the Saturation $\mathrm{L}^{-1}$ (S) of calcite and aragonite in incubation waters DIC* and SI werean concentrat Dssuming that $\mathrm{T}^{\circ} 0^{\circ} \mathrm{C}$, nnd $\mathrm{Cl}^{-}-\mathrm{Na}^{+}$in the assuming that $T$ ' $0^{\circ}$, and that

\begin{tabular}{|c|c|c|c|c|c|c|c|c|c|c|c|}
\hline Sample & $\mathrm{Cl}^{-}$ & $\mathrm{NO}_{3}^{-}$ & $\mathrm{SO}_{4}^{2-}$ & $\mathrm{K}^{+}$ & $\mathrm{Mg}^{2+}$ & $\mathrm{Ca}^{2+}$ & DO & $\mathrm{pH}$ & DIC* & SIragagnite & SI calcite \\
\hline DIW (initial) & 0 & 0 & 0 & 0 & 0 & 0 & 100 & 5.55 & 32.2 & $\mathrm{n} / \mathrm{a}$ & $\mathrm{n} / \mathrm{a}$ \\
\hline Light (final) & 4.11 & 0 & 23.3 & 37.1 & 0.25 & 290 & 122 & 9.97 & 241 & -0.08 & +0.09 \\
\hline St dev. & 0.01 & 0.04 & 8.84 & 0.50 & 8.34 & 68.7 & 8.06 & 0.49 & $n / a$ & $n / a$ & $n / a$ \\
\hline T-Test (initial vs. light) & 0.00 & 0.00 & 0.08 & 0.00 & 0.49 & 0.05 & 0.07 & 0.06 & 0.15 & $\mathrm{n} / \mathrm{a}$ & $\mathrm{n} / \mathrm{a}$ \\
\hline Dark (final) & 4.84 & 61.9 & 24.9 & 71.1 & 48.6 & 735 & 22.5 & 8.66 & 761 & -0.24 & -0.40 \\
\hline St dev. & 1.02 & 11.75 & 6.18 & 8.32 & 9.54 & 131 & 16.4 & 0.01 & $n / a$ & $n / a$ & $n / a$ \\
\hline T-Test (initial vs. dark) & 0.05 & 0.04 & 0.06 & 0.03 & 0.04 & 0.04 & 0.05 & 0.00 & 0.02 & $\mathrm{n} / \mathrm{a}$ & $\mathrm{n} / \mathrm{a}$ \\
\hline T-Test (light vs. dark) & 0.25 & 0.04 & 0.45 & 0.06 & 0.01 & 0.10 & 0.05 & 0.08 & 0.01 & $\mathrm{n} / \mathrm{a}$ & $\mathrm{n} / \mathrm{a}$ \\
\hline
\end{tabular}
final light vs, final dark bottles.

\section{Conclusions}

Short-term field and longer-term laboratory incubations demonstrate that autotrophic and heterotrophic processes in glacier surface sediments are closely linked. In the short term, carbon consumption equals or exceeds production if the initial DIC concentrations in the waters are low. This is particularly the case when the sediment depth is sufficient to eliminate light beyond surface layers. If however, there are sufficient carbonate minerals in the sediment which dissolve to provide additional DIC for fixing, net heterotrophy may eventually give rise to net autotrophy. The rate at which this occurs depends on dissolution of carbonate minerals and diffusion of DIC through the sediment into the surface; hence there is a relationship between primary production in cryoconite and sediment depth, as has previously been reported. We hypothesise that fixation of DIC from carbonate dissolution and the consequence recycling of organic matter has the 
potential to form radiocarbon old DOC from otherwise young organic matter These results demonstrate that microbial communities on glacier surfaces do have the potential to accumulate carbon on timescales of months to years.

\section{Acknowledgements}

This work was supported by EPSRC grant EP/D057620/1, NERC grant NE/ I008845/1 and NSF grant ANT-0423595. Fieldwork was conducted with the McMurdo Dry Valleys LTER and Antarctica New Zealand K064 site teams whose support is gratefully acknowledged, with logistics provided by Raytheon Polar Services and PHI Helicopters. Three anonymous reviewers provided helpful suggestions which improved the manuscript.

\section{Editor: Eric H. Oelkers}

\section{Additional Information}

Supplementary Information accompanies this letter at www.geochemicalperspectivesletters.org/article1605

Reprints and permission information is available online at http://www. geochemicalperspectivesletters.org/copyright-and-permissions

Cite this letter as: Bagshaw, E.A., Tranter, M., Wadham, J.L., Fountain, A.G., Dubnick, A., Fitzsimons, S. (2016) Processes controlling carbon cycling in Antarctic glacier surface ecosystems. Geochem. Persp. Let. 2, 44-54.

\section{References}

Anesio, A.M., Hodson, A.J., FritZ, A., Psenner, R., SAttler, B. (2009) High microbial activity on glaciers: importance to the global carbon cycle. Global Change Biology 15, 955-960, doi 10.1111/j.1365-2486.2008.01758.x.

Anesio, A.M., Laybourn-ParRY, J. (2012) Glaciers and ice sheets as a biome. Trends in Ecology \& Evolution 27, 4, 219-225, doi: 10.1016/j.tree.2011.09.012.

Bagshaw, E.A., Tranter, M., Fountain, A.G., Welch, K., Basagic, H.J., Lyons, W.B. (2007) Biogeochemical evolution of cryoconite holes on Canada Glacier, Taylor Valley, Antarctica. Journal of Geophysical Research-Biogeosciences 112, 8, doi: 10.1029/2007ig000442.

Bagshaw, E.A., Tranter, M., Wadham, J.L., Fountain, A.G., Basagic, H. (2010) Dynamic behaviour of supraglacial lakes on cold polar glaciers: Canada Glacier, McMurdo Dry Valleys, Antarctica. Journal of Glaciology 56, 196, 366-368.

Bagshaw, E.A., Tranter, M., Wadham, J.L., Fountain, A.G., Mowlem, M. (2011) High-resolution monitoring reveals dissolved oxygen dynamics in an Antarctic cryoconite hole. Hydrological Processes 25, 2868-2877, doi: 10.1002/hyp.8049.
Bagshaw, E.A., Stibal, M., Anesio, A.M., Bellas, C., Tranter, M., Telling, J., Wadham, J.L. (2012) Glacier Surface Habitats. In: Bell, E.M. (2012) Life at Extremes: Environments, Organisms and Strategies for Survival. CAB International, Dunbeg, Argyll, UK, 537 pp.

Bagshaw, E.A., Tranter, M., Fountain, A.G., Welch, K., Basagic, H.J., Lyons, W.B. (2013) Do cryoconite holes have the potential to be significant sources of $\mathrm{C}, \mathrm{N}$ and $\mathrm{P}$ to downstream depauperate ecosystems of Taylor Valley, Antarctica? Arctic Antarctic and Alpine Research 45, 4.

Christner, B.C., KvitKo, B.H., ReEve, J.N. (2003) Molecular identification of Bacteria and Eukarya inhabiting an Antarctic cryoconite hole. Extremophiles 7, 177-183.

Foreman, C.M., WolF, C.F., PRISCU, J.C. (2004) Impact of episodic warming events on the physical, chemical and biological relationships of lakes in the McMurdo Dry Valleys, Antarctica. Aquatic Geochemistry 10, 239-268.

Foreman, C.M., Sattler, B., Mickuki, J., Porazinska, D., Priscu, J.C., Priscu, L. (2007) Metabolic Activity of Cryoconites in the Taylor Valley, Antarctica. Journal of Geophysical Research Biogeosciences 112, G04S32 doi: 10.1029/2006JG000358.

Fountain, A.G., Tranter, M., Nylen, T.H., Lewis, K.J., Mueller, D.R. (2004) Evolution of cryoconite holes and their contribution to meltwater runoff from glaciers in the McMurdo Dry Valleys, Antarctica. Journal of Glaciology 50, 35-45.

GRIBBON, P.W. (1979) Cryoconite holes on Sermikaysak, West Greenland. Journal of Glaciology 22 177-181.

Hodson, A., Anesio, A.M., Tranter, M., Fountain, A., Osborn, M., Priscu, J., LaybournPARRY, J., SATTLER, B. (2008) Glacial ecosystems. Ecological Monographs 78, 41-67.

Hodson, A., Cameron, K., Boggild, C., Irvine-Fynn, T., Langford, H., Pearce, D., BANWART, S. (2010a) The structure, biological activity and biogeochemistry of cryoconite aggregates upon an Arctic valley glacier: Longyearbreen, Svalbard. Journal of Glaciology 56, 349-362

Hodson, A., Boggild, C., Hanna, E., Huybrechts, P., Langford, H., Cameron, K., HOULDSWORTH, A. (2010b) The cryoconite ecosystem on the Greenland ice sheet. Annals of Glaciology 51, 123-129.

Hodson, A., Paterson, H., Westwood, K., Cameron, K., Laybourn-Parry, J. (2013) A blueice ecosystem on the margins of the East Antarctic ice sheet. Journal of Glaciology 59, 255-268, doi: 10.3189/2013JoG12J052.

Hood, E., Battin, T.J., Fellman, J., O’Neel, S., Spencer, R.G.M. (2015) Storage and release of organic carbon from glaciers and ice sheets. Nature Geoscience 8, 91-96, doi: 10.1038/ngeo2331.

LANGFord, H., Hodson, A., BANwart, S., Boggild, C. (2010) The microstructure and biogeochemistry of Arctic cryoconite granules. Annals of Glaciology 51, 87-94.

Lawson, E.C., Wadham, J.L., Tranter, M., Stibal, M., Lis, G.P., Butler, C.E.H., Laybourn Parry, J., Nienow, P., Chandler, D., DewsburY, P. (2014) Greenland Ice Sheet exports labile organic carbon to the Arctic oceans. Biogeosciences 11, 14, 4015-4028, doi: 10.5194/ bg-11-4015-2014

NKem, J.N., Wall, D.H., Virginia, R.A., BarRetT, J.E., Broos, E.J., Porazinska, D.L., Adams, B.J. (2006) Wind dispersal of soil invertebrates in the McMurdo Dry valleys, Antarctica. Polar Biology 29, 346-352.

StibaL, M., TRANTER, M. (2007) Laboratory investigation of inorganic carbon uptake by cryoconite debris from Werenskioldbreen, Svalbard. Journal of Geophysical Research-Biogeosciences 112, 9.

TAKEUCHI, N., NishiYAMA, H., LI, Z. (2010) Structure and formation process of cryoconite granules on Ürümqi glacier No. 1, Tien Shan, China. Annals of Glaciology 51, 9-14, doi: 10.3189/172756411795932010 
Telling, J., Anesio, A.M., Hawkings, J., Tranter, M., Wadham, J.L., Hodson, A.J., IrvineFYNN, T., YALLOP, M.L. (2010) Measuring rates of gross photosynthesis and net community production in cryoconite holes: a comparison of field methods. Annals of Glaciology 51, 153-162.

Telling, J., Anesio, A.M., Tranter, M., Stibal, M., Hawkings, J., Irvine-Fynn, T., Hodson, A., ButLer, C., YAlLop, M.L., WADHAM, J. (2012) Controls on the autochthonous production and respiration of organic matter in cryoconite holes on High Arctic glaciers. Journal of tion and respiration of organic matter in cryoconite holes on High Arctic g

Tranter, M., Fountain, A.G., Fritsen, C.H., Lyons, W.B., Priscu, J.C., Statham, P.J., WELCH K.A. (2004) Extreme hydrochemical conditions in natural microcosms entombed within Antarctic ice. Hydrological Processes 18, 379-387.

Wilson, T.R.S., Thomson, J., Colley, S., Hydes, D.J., Higgs, N.C., Sørensen, J. (1985) Early organic diagenesis: The significance of progressive subsurface oxidation fronts in pelagic sediments. Geochimica et Cosmochimica Acta 49, 811-822, doi: 10.1016/0016-7037(85)90174-7. 